\title{
HIGIENE DAN SANITASI DEPOT AIR MINUM ISI ULANG DI KECAMATAN BANYUWANGI KABUPATEN BANYUWANGI JAWA TIMUR : KAJIAN DESKRIPTIF
}

\author{
HYGIENE AND SANITATION OF DEPOT DRINKING WATER OF \\ REFILL IN BANYUWANGI DISTRICT, BANYUWANGI EAST JAVA \\ DISTRICT:DESCRIPTIVE STUDY
}

\author{
Widatul Mila $^{1 *}$, Sayu Larasati Nabilah ${ }^{1}$, Septa Indra Puspikawati ${ }^{2}$ \\ ${ }^{1}$ Departemen Kesehatan Lingkungan, Fakultas Kesehatan Masyarakat \\ PSDKU Universitas Airlangga \\ ${ }^{2}$ Departemen Gizi Kesehatan, Fakultas Kesehatan Masyarakat \\ PSDKU Universitas Airlangga \\ *email: widatul.mila-2016@fkm.unair.ac.id
}

\begin{abstract}
Water is a vital need in daily life because all living things need water. Over time, the fulfillment of the need for drinking water for the community varies greatly. This condition makes the community have another alternative to consume drinking water, which is drinking water produced by the Refill Drinking Water Depot (DAMIU). Refill drinking water has a lower price, but not all quality refillable drinking water depots are guaranteed. The purpose of this study was to determine DAMIU sanitation hygiene in Banyuwangi District, Banyuwangi Regency, East Java Province. This research is a descriptive study with observation and interview methods to managers or employees of refill drinking water depots using the instrument of observation of hygiene and sanitation depot drinking water which was adopted from the Regulation of the Minister of Health of the Republic of Indonesia Number 43 of 2014 concerning Sanitation Hygiene of Drinking Water Depots. The results showed that there were 2 (6.67\%) DAMIU that did not meet the physical eligibility requirements and 28 (93.33\%) DAMIU met the physical eligibility requirements. The conclusion of this research is that hygiene and sanitation conditions in 30 DAMIU in Banyuwangi District are generally good, but intensive guidance and supervision by the Banyuwangi District Health Office needs to be done for the Refill Drinking Water Depot in Banyuwangi District.
\end{abstract}

Keywords: Hygiene, sanitation, DAMIU

\begin{abstract}
Abstrak
Air adalah kebutuhan vital dalam kehidupan sehari-hari karena semua makhluk hidup membutuhkan air. Seiring berjalannya waktu, pemenuhan kebutuhan akan air minum bagi masyarakat sangat bervariasi. Kondisi ini membuat masyarakat memiliki alternatif lain untuk mengkonsumsi air minum yaitu air minum yang diproduksi oleh Depot Air Minum Isi Ulang (DAMIU). air minum isi ulang memiliki harga yang lebih murah namun tidak semua depot air minum isi ulang kualitasnya terjamin. Tujuan penelitian ini adalah untuk mendeskripsikan higiene sanitasi DAMIU di Kecamatan Banyuwangi, Kabupaten Banyuwangi, Propinsi Jawa Timur. Penelitian ini merupakan penelitian deskriptif dengan metode observasi dan wawancara kepada pengelola atau karyawan depot air minum isi ulang yang menggunakan instrumen lembar observasi higiene dan sanitasi depot air minum yang diadopsi dari Peraturan Menteri Kesehatan Republik Indonesia Nomor 43 Tahun 2014 tentang Higiene Sanitasi Depot Air Minum. Hasil menunjukkan terdapat 2 (6,67\%) DAMIU yang tidak memenuhi syarat kelaikan fisik dan $28(93,33 \%)$ DAMIU memenuhi syarat kelaikan fisik. Kesimpulan penelitan ini adalah kondisi higiene dan sanitasi di 30 DAMIU di Kecamatan Banyuwangi secara umum sudah baik, namun perlu dilakukan upaya pembinaan dan pengawasan secara intensif oleh Dinas Kesehatan Kabupaten Banyuwangi terhadap Depot Air Minum Isi Ulang di Kecamatan Banyuwangi.
\end{abstract}

Kata Kunci: Higiene, sanitasi, DAMIU 


\section{PENDAHULUAN}

Air merupakan kebutuhan yang sangat vital dalam kehidupan sehari-hari. Air dimanfaatkan oleh manusia untuk berbagai keperluan, misalnya untuk keperluan minum, mandi, mencuci dan kegiatan lainnya (Citra, 2016). Kebutuhan akan air pada setiap manusia berbeda-beda tergantung pada tempat dan tingkatan kebutuhan. Penggunaan air yang paling penting bagi manusia adalah untuk minum. Menurut Peraturan Menteri Kesehatan Nomor 43 Tahun 2014 menyebutkan bahwa air minum merupakan air yang melalui proses pengolahan atau tanpa melalui proses pengolahan yang memenuhi syarat kesehatan dan dapat diminum secara langsung (Menteri Kesehatan Republik Indonesia, 2014).

Seiring berjalannya waktu, pemenuhan kebutuhan akan air minum bagi masyarakat sangat bervariasi. Terdapat masyarakat yang mengambil air minum bersumber dari mata air, air sungai, air tanah yang menggunakan sumur dalam atau sumur dangkal serta air perpipaan yang di produksi oleh Perusahaan Umum Daerah Air Minum (PUDAM) setempat yang dikonsumsi setelah di masak. industrialisasi dalam penyediaan air minum ada untuk memenuhi kebutuhan air bagi kebutuhan manusia. Air Minum Dalam Kemasan (AMDK) menjadi alternatif lain yang dijadikan sebagai salah satu sumber air minum. Air Minum Dalam Kemasan dipilih oleh masyarakat karena dianggap lebih praktis dan higienis. Namun, lama kelamaan masyarakat merasa bahwasanya Air Minum Dalam Kemasan dari berbagai merk harganya semakin mahal, sehingga konsumen menemukan alternatif lain yaitu dengan mengkonsumsi air minum yang diproduksi oleh Depot Air Minum Isi Ulang.

DAMIU adalah badan usaha yang mengelolah air minum untuk keperluan masyarakat dalam bentuk curah dan tidak dikemas. Jika dilihat dari harganya, air minum isi ulang lebih murah dibandingkan dengan air minum dalam kemasan. Meskipun harga air minum isi ulang lebih murah, tidak semua depot air minum isi ulang kualitasnya terjamin. Masyarakat masih meragukan karena belum adanya informasi yang jelas terkait proses maupun peraturan tentang peredaran dan pengawasan air minum isi ulang. Kondisi ini mengakibatkan terdapat beberapa depot air minum isi ulang yang tidak memenuhi standar persyaratan yang ditentukan. Jika tidak dikendalikan secara maksimal, depot air minum memiliki potensi menimbulkan kerugian bagi kesehatan, misalnya keracunan zat kimia persisten maupun penyebaran penyakit melalui air atau food borne disease (Rietveld et al., 2008).

Berdasarkan penelitian yang dilakukan oleh Selomo et al. (2018), menyatakan bahwa dari 9 DAMIU di Kecamatan Campalagian Kabupaten Polewangi Mandar, terdapat 5 depot atau sebesar $55,67 \%$ yang memenuhi kelaikan fisik sedangkan 44,44\% tidak memenuhi kelaikan fisik. Kondisi ini menunjukkan bahwasanya pelaksanaan kegiatan di DAMIU masih perlu mendapatkan pengawasan khusus. Oleh karena itu, dalam menjalankan kegiatan di DAMIU harus memperhatikan beberapa aspek seperti aspek kebersihan dan perilaku penjamah serta ketersediaan sarana sanitasi dasar. Sehingga, diperlukan adanya inspeksi terkait dengan pengelolaan, pembinaan serta pengawasan kualitas air terhadap depot air minum yang berdasarkan Peraturan Menteri Kesehatan Nomor 43 Tahun 2014. Penelitian ini bertujuan untuk mengetahui higiene dan sanitasi DAMIU di Kecamatan Banyuwangi, Kabupaten Banyuwangi, Propinsi Jawa Timur.

\section{METODE PENELITIAN}

Penelitian ini merupakan penelitian deskriptif. Populasi penelitian adalah seluruh Depot Air Minum Isi Ulang (DAMIU) yang berada di Kecamatan Banyuwangi berjumlah 30 DAMIU yang diambil semua sebagai sampel (total sampling). Pada variabel penjamah dilakukan dengan mewawancarai responden pengelola atau karyawan DAMIU. Penelitian ini dilakukan pada bulan Mei 2019.

Pengambilan data dilakukan dengan observasi menggunakan instrumen lembar observasi higiene dan sanitasi depot air minum. Dalam melakukan penelitian, peneliti menggunakan lembar observasi yang diadopsi dari Peraturan Menteri Kesehatan Republik Indonesia Nomor 43 Tahun 2014 tentang Higiene Sanitasi Depot Air Minum. Pada penelitian ini terdapat 4 variabel yang meliputi variabel tempat, variabel peralatan, variabel penjamah dan variebel air baku. Pada masingmasing variabel tersebut akan dinilai dengan cara menjumlahkan objek yang memenuhi syarat dengan jumlah maksimal penilaian 100. Jika 
hasil penilaian semua variabel mendapatkan nilai 70 atau lebih, maka depot air minum isi ulang dinyatakan memenuhi syarat (MS) kelaikan fisik, akan tetapi jika nilai pemeriksaan berada di bawah 70, maka depot air minum isi ulang tidak memenuhi syarat (TMS) kelaikan fisik sehingga pengelola depot diminta untuk memperbaiki obyek depot yang bermasalah. Data yang diperoleh dari penelitian ini disajikan dalam bentuk tabel dan narasi.

\section{HASIL DAN PEMBAHASAN}

Hasil penelitian dan pembahasan mengenai gambaran higiene dan sanitasi DAMIU pada 30 DAMIU di Kecamatan Banyuwangi disajikan pada Tabel 1.

Tabel 1 menunjukkan bahwa Sanitasi tempat yang diteliti di DAMIU Kecamatan Banyuwangi meliputi lokasi, kondisi bangunan; lantai; dinding; atap, langit- langit dan pembagian tata ruang; Pencahayaan, ventilasi, dan kelembapan; serta fasilitas sanitasi. Hasil observasi pada higiene dan sanitasi DAMIU untuk variabel tempat, belum semuanya memenuhi syarat. Hal ini tidak sejalan dengan penelitian yang dilakukan oleh Pandeinuwu et al. (2016), yang menyebutkan bahwa higiene sanitasi depot air minum isi ulang di Kota Tomohon sudah memenuhi syarat di 15 depot $(100 \%)$.

Banyuwangi, Kabupaten Banyuwangi Tahun 2019

\begin{tabular}{|c|c|c|c|c|c|}
\hline \multirow[t]{2}{*}{ No. } & \multirow[t]{2}{*}{ Kondisi Higiene dan Sanitasi Depot } & \multicolumn{2}{|c|}{ MS } & \multicolumn{2}{|c|}{ TMS } \\
\hline & & $\mathbf{n}$ & $\%$ & $\mathbf{n}$ & $\%$ \\
\hline \multicolumn{6}{|c|}{ Tempat } \\
\hline 1. & $\begin{array}{l}\text { Lokasi bebas dari pencemaran dan penularan } \\
\text { penyakit }\end{array}$ & 26 & 86,67 & 4 & 13,33 \\
\hline 2. & $\begin{array}{l}\text { Bangunan kuat, aman, mudah dibersihkan dan } \\
\text { mudah pemeliharaannya }\end{array}$ & 27 & 90 & 3 & 10 \\
\hline 3. & $\begin{array}{l}\text { Lantai kedap air, permukaan rata, halus, tidak licin, } \\
\text { tidak retak, tidak menyerap debu, dan mudah } \\
\text { dibersihkan, serta kemiringan cukup landai }\end{array}$ & 26 & 86,67 & 4 & 13,33 \\
\hline & Dinding kedap air, permukaan rata, halus, tidak & 29 & 96,67 & 1 & 3,33 \\
\hline 4. & $\begin{array}{l}\text { licin, tidak retak, tidak menyerap debu, dan mudah } \\
\text { dibersihkan, serta warna yang terang dan cerah }\end{array}$ & & & & \\
\hline 5. & $\begin{array}{l}\text { Atap dan langit-langit harus kuat, anti tikus, mudah } \\
\text { dibersihkan, tidak menyerap debu, permukaan rata, } \\
\text { dan berwarna terang, serta mempunyai ketinggian } \\
\text { cukup }\end{array}$ & 25 & 83,33 & 5 & 16,67 \\
\hline 6. & $\begin{array}{l}\text { Tata ruang terdiri atas ruang proses pengolahan, } \\
\text { penyimpanan, pembagian atau penyediaan, dan } \\
\text { ruang tunggu pengunjung/konsumen }\end{array}$ & 25 & 83,33 & 5 & 16,67 \\
\hline 7. & $\begin{array}{l}\text { Pencahayaan cukup terang untuk bekerja, tidak } \\
\text { menyilaukan dan tersebar secara merata }\end{array}$ & 29 & 96,67 & 1 & 3,33 \\
\hline
\end{tabular}

Komponen lokasi DAMIU di Kecamatan Banyuwangi terdapat 4 (13,33\%) DAMIU yang tidak memenuhi syarat dikarenakan lokasinya berada di sepanjang jalan raya, sehingga memungkinkan debu atau asap kendaraan bermotor dapat mencemari lokasi DAMIU. Selain itu, terdapat lokasi DAMIU yang berada di dekat pembuangan sampah sementara sehingga berpotensi menimbulkan pencemaran terhadap air minum isi ulang. Menurut Purwana (2006), persyaratan DAMIU harus memiliki bangunan yang berada di lokasi yang terbebas dari pencemaran tempat pembuangan kotoran dan sampah penumpukan barang-barang bekas atau berbahaya (B3) dan daerah lain yang diduga dapat menimbulkan pencemaran terhadap air minum. Komponen bangunan DAMIU menunjukkan sebesar 3 (10\%) DAMIU tidak memenuhi syarat dikarenakan terdapat DAMIU yang bangunannya terbuat dari papan atau triplek sehingga berpotensi rusak dan debu yang berada di luar ruangan mudah masuk sehingga bisa menimbulkan pencemaran, namun 27 (90\%) DAMIU lainnya memiliki bangunan yang permanen. Komponen lantai yang tidak memenuhi persyaratan sebesar 4 (13,33\%) DAMIU, dikarenakan kondisi lantai yang mengalami retak dan tidak kedap air sehingga sulit untuk dibersihkan dan lantainya tidak landai sehingga memungkinkan air mudah tergenang.
Tabel 1. Gambaran Kondisi Sanitasi Tempat Depot Air Minum Isi Ulang (DAMIU) di Kecamatan 
Tabel 1. Gambaran Kondisi Sanitasi Tempat Depot Air Minum Isi Ulang (DAMIU) di Kecamatan Banyuwangi, Kabupaten Banyuwangi Tahun 2019 (lanjutan)

\begin{tabular}{|c|c|c|c|c|c|}
\hline \multirow[t]{2}{*}{ No. } & \multirow{2}{*}{ Kondisi Higiene dan Sanitasi Depot } & \multicolumn{2}{|c|}{ MS } & \multicolumn{2}{|c|}{ TMS } \\
\hline & & $\mathbf{N}$ & $\%$ & $\mathbf{n}$ & $\%$ \\
\hline 8. & $\begin{array}{l}\text { Ventilasi menjamin peredaraan/pertukaran } \\
\text { udara dengan baik }\end{array}$ & 27 & 90 & 3 & 10 \\
\hline 9. & $\begin{array}{l}\text { Kelembaban udara dapat memberikan mendukung } \\
\text { kenyamanan dalam melakukan pekerjaan/aktivitas }\end{array}$ & 28 & 93,33 & 2 & 6,67 \\
\hline 10. & Memiliki akses kamar mandi danjamban & 24 & 80 & 6 & 20 \\
\hline 11. & $\begin{array}{l}\text { Terdapat saluran pembuangan air limbah yang } \\
\text { alirannya lancar dan tertutup }\end{array}$ & 25 & 83,33 & 5 & 16,67 \\
\hline 12. & Terdapat tempat sampah yangtertutup & 10 & 33,33 & 20 & 66,67 \\
\hline 13. & $\begin{array}{l}\text { Terdapat tempat cuci tangan yang dilengkapi air } \\
\text { mengalir dan sabun }\end{array}$ & 7 & 23,33 & 23 & 76,67 \\
\hline 14. & Bebas dari tikus, lalat dan kecoa & 26 & 86,67 & 4 & 13,33 \\
\hline
\end{tabular}

Sumber: Data Primer, 2019

Hasil penelitian DAMIU di Kecamatan Banyuwangi, menunjukkan terdapat $1(3,33 \%)$ DAMIU yang dindingnya tidak memenuhi syarat. Hal ini dikarenakan dindingnya sudah retak dan kurang dijaga kebersihannya. Dinding yang terbuat dari papan, mudah menyerap air dan menyebabkan tumbuhnya lumut sehingga sulit untuk dibersihkan Menurut Kementrian Kesehatan RI Nomor 43 Tahun 2014 menyebutkan bahwa dinding DAMIU harus kedap air, permukaan rata, halus, tidak licin, tidak retak, tidak menyerap debu, dan mudah dibersihkan, serta warna yang terang dan cerah. Pada komponen atap bangunan DAMIU, terdapat $5(16,67 \%)$ DAMIU yang tidak memenuhi syarat. Dinding yang terbuat dari papan mudah menyerap air dan menyebabkan tumbuhnya lumut sehingga sulit untuk dibersihkan. Selanjutnya mengenai pembagian tata ruang depot, berdasarkan hasil penelitian menunjukkan bahwa tata ruang depot sebanyak $16,67 \%$ tidak memenuhi syarat. Sebanyak 5 DAMIU tidak terdapat pembagian atau sekat antara ruang pengolahan, penyimpanan, penyediaan dan ruang tunggu konsumen. Pencahayaan pada 1 (3,33\%) DAMIU tidak memenuhi persyaratsn dan terdapat $27 \quad(90 \%)$ DAMIU yang bangunannya dilengkapi dengan ventilasi sehingga menjamin peredaraan/ pertukaran udara sehingga sesuai dengan ketentuan pada Peraturan Menteri Kesehatan Nomor 43 Tahun 2014, akan tetapi pada 3 DAMIU lainnya, ventilasi dalam bangunan belum memenuhi syarat. Adanya ventilasi yang cukup, dapat memudahkan terjadinya pertukaran udara di dalam bangunan DAMIU. Ventilasi sangat penting sebagai tempat petukaran udara, sehingga suhu di dalam ruangan sama dengan suhu di di luar ruangan.
Selain itu, pertukaran udara sangat penting bagi kesehatan pekerja yang berada di dalam DAMIU tersebut. Ada 24 (80\%) DAMIU yang terfasilitasi dengan kamar mandi dan jamban, sedangkan yang tidak memenuhi syarat sebanyak 6 (20\%) DAMIU. Pada saluran pembuangan air limbah, terdapat $5(16,67 \%)$ DAMIU tidak memenuhi syarat, dikarenakan saluran pembuangan air limbahnya lancar akan tetapi tidak tertutup. Hanya terdapat $10(33,33 \%)$ DAMIU yang memiliki tempat sampah tertutup, sedangkan $20 \quad(66,67 \%)$ DAMIU tidak dilengkapi dengan tempat sampah dan terdapat tempat sampah yang terbuka. Di beberapa DAMIU tersebut, tempat sampah dibiarkan terbuka bahkan sebagian sampah sampai tumpah dan tercecer dikarenakan volumenya melebihi kapasitas. Tempat sampah yang menggunung memegang peran penting dalam upaya penyebaran penyakit.

Hasil penelitian menunjukkan bahwa sarana cuci tangan di DAMIU Kecamatan Banyuwangi hanya terdapat 7 DAMIU $(23,33 \%)$ yang terfasilitasi sarana tersebut secara lengkap yaitu adanya air mengalir dan menggunakan sabun. Pemilik DAMIU biasanya menggunakan keran pencuci galon atau kamar mandi ketika hendak mencuci tangan. Sementara 23 (76,67\%) DAMIU tidak terdapat fasilitas cuci tangan. Hasil penelitian ini sejalan dengan penelitian yang dilakukan oleh Sukmara (2002) yang menyebutkan bahwa fasilitas sanitasi yang tidak memenuhi persyaratan memiliki risiko 9,214 kali terkontaminasi E.coli dibandingkan dengan fasilitas sanitasi yang memenuhi persyaratan. Terdapat 4 $(13,33 \%)$ DAMIU yang tidak memenuhi syarat sesuai dengan Peraturan Menteri Kesehatan Nomor 43 Tahun 2014 yaitu DAMIU bebas dari tikus, lalat dan kecoa. DAMIU tersebut 
Tabel 2. Gambaran Kondisi Sanitasi Peralatan Depot Air Minum Isi Ulang (DAMIU) di Kecamatan Banyuwangi, Kabupaten Banyuwangi Tahun 2019

\begin{tabular}{|c|c|c|c|c|c|}
\hline \multirow[t]{2}{*}{ No. } & \multirow[t]{2}{*}{ Kondisi Higiene dan Sanitasi Depot } & \multicolumn{2}{|c|}{ MS } & \multicolumn{2}{|c|}{ TMS } \\
\hline & & $\mathbf{N}$ & $\%$ & $\mathbf{n}$ & $\%$ \\
\hline \multicolumn{6}{|c|}{ Peralatan } \\
\hline 1. & $\begin{array}{l}\text { Peralatan yang digunakan terbuat dari bahan tara } \\
\text { pangan }\end{array}$ & 29 & 96,67 & 1 & 3,33 \\
\hline 2. & $\begin{array}{l}\text { Mikrofilter dan peralatan desinfeksi masih dalam masa } \\
\text { pakai/tidak kadaluarsa }\end{array}$ & 29 & 96,67 & 1 & 3,33 \\
\hline 3. & Tandon air baku harus tertutup dan terlindung & 30 & 100 & 0 & 0,00 \\
\hline 4. & $\begin{array}{l}\text { Wadah/botol galon sebelum pengisian dilakukan } \\
\text { pembersihan }\end{array}$ & 30 & 100 & 0 & 0,00 \\
\hline 5. & $\begin{array}{l}\text { Wadah/galon yang telah diisi air minum harus } \\
\text { langsung diberikan kepada konsumen dan tidak boleh } \\
\text { disimpan pada DAM lebih dari } 1 \times 24 \text { jam }\end{array}$ & 29 & 96,67 & 1 & 3,33 \\
\hline 6. & $\begin{array}{l}\text { Melakukan sistem } \\
\text { (back washing) secara } \\
\text { macro filter. }\end{array}$ & 30 & 100 & 0 & 0,00 \\
\hline 7. & $\begin{array}{l}\text { Terdapat lebih dari satu mikro filter }(\mu) \text { dengan ukuran } \\
\text { berjenjang }\end{array}$ & 30 & 100 & 0 & 0,00 \\
\hline 8. & $\begin{array}{l}\text { Terdapat peralatan sterilisasi, berupa ultra violet dan } \\
\text { atau ozonisasi dan atau peralatan disinfeksi lainnya } \\
\text { yang berfungsi dan digunakan secara benar }\end{array}$ & 30 & 100 & 0 & 0,00 \\
\hline 9. & Ada fasilitas pencucian dan pembilasan botol (galon) & 30 & 100 & 0 & 0,00 \\
\hline & $\begin{array}{l}\text { Ada fasilitas pengisian botol (galon) dalam } \\
\text { ruangan tertutup }\end{array}$ & 30 & 100 & 0 & 0,00 \\
\hline 11. & Tersedia tutup botol baru yang bersih & 30 & 100 & 0 & 0,00 \\
\hline
\end{tabular}

Sumber: Data Primer, 2019

terletak di sekitar pasar sehingga kemungkinan terdapat hewan penyebar penyakit seperti tikus, kecoa dan lalat yang dapat mengotori atau merusak peralatan DAMIU.

Berdasarkan Tabel 2, menunjukkan bahwa secara umum kondisi sanitasi peralatan DAMIU di Kecamatan Banyuwangi sudah baik, hampir semua variabel telah memenuhi persyaratan. Sejalan dengan penelitian Hayu et al. (2018), yang menjelaskan bahwa semua peralatan DAMIU di Kelurahan Pesisir, Kecamatan Lima Puluh Pekanbaru telah memenuhi syarat (100\%), kondisi ini dikarenakan peralatan yang terbuat dari bahan food grade.

Dalam menjalankan kegiatan di DAMIU harus memenuhi persyaratan yang sesuai standar. Begitupun pada peralatan yang digunakan DAMIU harus diperhatikan kondisi dan fungsinya agar air minum isi ulang yang dihasilkan terhindar dari pencemaran. Hasil penelitian menunjukkan terdapat $1 \quad(3,33 \%)$ DAMIU yang tidak memenuhi syarat. Menurut Asfawi (2004), peralatan memiliki peran penting dalam mengolah air baku menjadi air minum. Kondisi peralatan yang baik dan memenuhi persyaratan diharapkan dapat menghasil-kan air minum yang baik dan sesuai dengan standar.
Berdasarkan Peraturan Menteri Kesehatan Nomor 43 tahun 2014, DAMIU harus dilengkapi dengan peralatan dan perlengkapan yang terdiri dari pengisian air baku, tandon air baku, pompa penghisap dan penyedot, filter, mikrofilter, wadah/galon, kran penghubung, dan peralatan desinfeksi harus terbuat dari bahan tara pangan (food grade) atau tidak menimbulkan racun, tidak menyerap bau dan rasa, tahan karat, tahan pencucian dan tahan desinfeksi ulang; mikrofilter dan desinfektor tidak kadaluarsa; tandon air baku harus tertutup dan terlindung; wadah/galon untuk air baku atau air minum sebelum dilakukan pengisian harus dibersihkan dengan cara dibilas terlebih dahulu dengan air produksi paling sedikit selama 10 (sepuluh) detik dan setelah pengisian diberi tutup yang bersih; serta wadah/galon yang telah diisi air minum harus langsung diberikan kepada konsumen dan tidak boleh disimpan pada DAMIU lebih dari 1x24 jam (Menteri Kesehatan Republik Indonesia, 2014)

Hasil penelitian menunjukkan terdapat 1 DAMIU $(3,33 \%)$ yang menyimpan air minum isi ulang dalam wadah/galon lebih dari 1x24 jam. Hal ini harus menjadi perhatian bagi pemilik DAMIU dalam penyimpanan air minum, dikarenakan penyimpanan air minum isi ulang 
tidak boleh melebihi 24 jam. Menurut Fitri (2010), penyimpanan air baku dalam waktu yang lama dapat berpengaruh terhadap kualitas air minum, misalnya bakteri akan tumbuh dengan banyak, kebutuhan oksigen untuk mengoksidasi bahan kimia secara kimiawi semakin meningkat, serta menurunnya $\mathrm{pH}$, kesadahan, dan kandungan ion $\mathrm{Fe}$. Hal ini sejalan dengan penelitian yang dilakukan oleh Nuria et al. (2009), menyebutkan bahwa penyimpanan air di dalam penampungan yang lama, dapat menyebabkan adanya kontaminasi E.coli, sehingga hal tersebut berpengaruh terhadap kualitas sumber air baku yang digunakan. adanya kontaminasi selama memasukkan air ke dalam tangki pengangkutan, tempat penampungan yang kurang bersih, proses pengolahan yang kurang optimal, dan kebersihan lingkungan di sekitas DAMIU kurang diperhatikan.

Gambaran kondisi higiene penjamah DAMIU ditunjukkan oleh Tabel 3. Hasil observasi pada variabel perilaku penjamah atau karyawan yang mencuci tangan dengan menggunakan sabun dan air mengalir masih rendah dalam melayani konsumen air minum isi ulang yaitu sebanyak 6 (20\%) DAMIU yang melakukan, selain itu, penjamah yang menggunakan pakaian kerja saat bekerja hanya dilakukan di 14 (46,67\%) DAMIU. Aktifitas yang dilakukan di DAMIU harus memperhatikan segi higiene dan sanitasi penjamah dan operator. Hal ini dikarenakan kegiatan yang dilakukan di DAMIU memungkinkan terjadi penyebaran penyakit. Penyebaran penyakit yang berasal dari makanan atau minuman dapat terjadi karena adanya karyawan yang mengkontaminasi peralatan maupun melakukan kontak secara langsung dengan makanan atau minuman, kemudian makanan atau minuman tersebut dikonsumsi oleh orang yang rentan. Apabila kondisi atau kekebalan tubuh seseorang kurang baik, maka dapat mengakibatkan penyakit bahkan pada kematian (Depkes RI, 1998). Perilaku lain yang berpotensi menimbulkan penyakit adalah tidak mencuci tangan. Karyawan atau operator DAMIU harus mencuci tangan sebelum melayani konsumen air minum isi ulang. Hal ini sejalan dengan penelitian Sulistyandari et al. (2009), yang menjelaskan bahwasanya dalam bekerja, pengolah makanan harus memperhatikan prosedur penting yang berupa mencuci tangan, menjaga kebersihan, dan kesehatan diri. Mencuci tangan merupakan salah satu cara untuk memutuskan rantai penyebaran penyakit.

Hasil penelitian menunjukkan hanya sebagian penjamah (50\%) dari 30 DAMIU di Kecamatan banyuwangi yang melakukan pemeriksaan kesehatan secara berkala. Pemeriksaan kesehatan sebaiknya dilakukan oleh penjamah DAMIU secara berkala minimal satu kali dalam satau tahun. Menurut Asfawi, seorang penjamah makanan atau minuman harus melakukan pemeriksaan kesehatan secara berkala yang dilakukan setiap enam bulan sekali. Hal ini sejalan dengan Purnawijayanti (2001), yang menyebutkan bahwa seorang penjamah makanan harus melakukan pemeriksaan terhadap kesehatannya secara berkala tiap enam bulan sekali. Karyawan yang bekerja di DAMIU juga harus memperhatikan penampilan saat bekerja.

Tabel 3. Gambaran Kondisi Higiene Penjamah Depot Air Minum Isi Ulang (DAMIU) di Kecamatan Banyuwangi, Kabupaten Banyuwangi Tahun 2019

\begin{tabular}{|c|c|c|c|c|c|}
\hline \multirow[t]{2}{*}{ No. } & \multirow[t]{2}{*}{ Kondisi Higiene dan Sanitasi Depot } & \multicolumn{2}{|c|}{ MS } & \multicolumn{2}{|c|}{ TMS } \\
\hline & & $\mathbf{n}$ & $\%$ & $\mathbf{n}$ & $\%$ \\
\hline \multicolumn{6}{|c|}{ Penjamah } \\
\hline 1. & Sehat dan bebas dari penyakit menular & 30 & 100 & 0 & 0,00 \\
\hline 2. & Tidak menjadi pembawa kuman penyakit & 30 & 100 & 0 & 0,00 \\
\hline 3. & Berperilaku higiene dan sanitasi setiap melayani konsumen & 15 & 50 & 15 & 50 \\
\hline 4. & $\begin{array}{l}\text { Selalu mencuci tangan dengan sabun dan air mengalir setiap } \\
\text { melayani konsumen }\end{array}$ & 6 & 20 & 24 & 80 \\
\hline 5. & Menggunakan pakaian kerja yang bersih dan rapi & 14 & 46,67 & 16 & 53,33 \\
\hline 6. & $\begin{array}{l}\text { Melakukan pemeriksaan kesehatan secara berkala minimal } 1 \\
\text { (satu) }\end{array}$ & 15 & 50 & 15 & 50,00 \\
\hline 7. & $\begin{array}{l}\text { Operator/penanggung jawab/pemilik memiliki sertifikat telah } \\
\text { mengikuti kursus higiene sanitasi depot air minum }\end{array}$ & 22 & 73,33 & 8 & 26,67 \\
\hline
\end{tabular}


Sebesar 53,33\% penjamah tidak menggunakan pakaian kerja yang bersih dan rapi saat bekerja di DAMIU. Berdasarkan obervasi yang dilakukan, pekerja dalam menjalankan kegiatan di DAMIU menggunakan pakaian sehari-hari.Kondisi ini tidak sejalan dengan BBPOM (2004), yang menyebutkan bahwa pakaian kerja sebaiknya bukan berasal dari pakaian biasa yang digunakan sehari-hari, namun pakaian yang digunakan dalam keadaan bersih dan sopan yang berwarna terang bermotif dan bersih. Warna terang pada pakaian lebih memudahkan seseorang untuk bisa mendeteksi jika terdapat kotoran pada baju yang berpotensi untuk mengkontaminasi pada produk makanan atau minuman (Purnawijayanti, 2001). Menurut Depkes RI (2006), operator harus memakai pakaian kerja yang bersih, berseragam, memakai tutup rambut dan khusus dipakai pada waktu bertugas, serta memakai tanda pengenal sehingga hanya petugas resmi yang bekerja. Operator harus melaksanakan praktek perilaku hidup bersih dan sehat (PHBS), tidak merokok sewaktu bekerja, tidak meludah atau bersin sembarangan, cara memegang galon yangbersih dan selalu membiasakan mencuci tangan pada waktu melayani konsumen. Selain itu, pada operator DAMIU sebaiknya memiliki sertifikat kursus higiene. Hasil penelitian menunjukkan bahwa $8(26,67 \%)$ operator/ penanggung jawab/pemilik DAMIU tidak memiliki sertifikat telah mengikuti kursus higiene sanitasi depot air minum.

Hasil pada Tabel 4 menunjukkan bahwa gambaran kondisi sanitasi air baku DAMIU hampir semuanya memenuhi persyaratan Hasil penelitian menunjukkan bahwa secara umum, sanitasi higiene air baku dan air minum di Kecamatan Banyuwangi sudah memenuhi persyaratan dengan baik. Menurut Permenkes Nomor 492 tahun 2010, air minum aman bagi kesehatan dan dapat dikonsumsi apabila memenuhi persyaratan yang telah ditetapkan, yaitu persyaratan fisika, mikrobiologis, kimia dan radioaktif. Hasil penelitan menunjukkan $100 \%$ bahan baku DAMIU memenuhi persyaratan fisik, mikrobiologi dan standar kimia. Berdasarkan Kepmenperindag Nomor 651 tahun 2004, menyatakan bahwasanya depot air minum isi ulang dilarang mengambil air baku yang berasal dari air PDAM yang terdapat dalam jaringan distribusi untuk rumah tangga. Bahan baku yang digunakan untuk keperluan DAMIU ini harus berasal dari sumber yang kualitasnya telah dijamin oleh Kepmenperindag Nomor 651 tahun 2004.

Tabel 4. Gambaran Kondisi Sanitasi Air Baku Depot Air Minum Isi Ulang (DAMIU) di Kecamatan Banyuwangi, Kabupaten Banyuwangi Tahun 2019

\begin{tabular}{|c|c|c|c|c|c|}
\hline \multirow[t]{2}{*}{ No. } & \multirow{2}{*}{ Kondisi Higiene dan Sanitasi Depot } & \multicolumn{2}{|c|}{ MS } & \multicolumn{2}{|c|}{ TMS } \\
\hline & & $\mathrm{N}$ & $\%$ & $\mathrm{n}$ & $\%$ \\
\hline \multicolumn{6}{|c|}{ Air Baku } \\
\hline 1. & $\begin{array}{l}\text { Bahan baku memenuhi persyaratan fisik, } \\
\text { mikrobiologi dan kimia standar }\end{array}$ & 30 & 100 & 0 & 0 \\
\hline 2. & $\begin{array}{l}\text { Pengangkutan air baku memiliki surat jaminan pasok } \\
\text { air baku }\end{array}$ & 28 & 93,33 & 2 & 6,67 \\
\hline 3. & $\begin{array}{l}\text { Kendaraan tangki air terbuat dari bahan yang tidak } \\
\text { dapat melepaskan zat-zat beracun ke dalam air/harus } \\
\text { tara pangan }\end{array}$ & 28 & 93,33 & 2 & 6,67 \\
\hline 4. & Ada bukti tertulis/sertifikat sumber air & 30 & 100 & 0 & 0 \\
\hline 5. & $\begin{array}{l}\text { Pengangkutan air baku paling lama } 12 \text { jam sampai } \\
\text { ke depot air minum dan selama perjalanan dilakukan } \\
\text { desinfeksi }\end{array}$ & 29 & 96,67 & 1 & 3,33 \\
\hline 6. & $\begin{array}{l}\text { Kualitas Air minum yang dihasilkan memenuhi } \\
\text { persyaratan fisik, mikrobiologi dan kimia standar } \\
\text { yang sesuai standar baku mutu atau persyaratan } \\
\text { kualitas air minum }\end{array}$ & 30 & 100 & 0 & 0 \\
\hline
\end{tabular}

Sumber: Data Primer, 2019

Hasil penelitian menunjukkan bahwa terdapat $28 \quad(93.33 \%)$ DAMIU, tentang kendaraan tangki yang mengangkut air terbuat dari bahan yang tidak dapat melepaskan zat-zat beracun ke dalam air/ harus tara pangan, sedangkan $2(6,67 \%)$ DAMIU lainnya tidak memenuhi syarat. Menurut Rahayu et al. (2008), air baku yang diambil dari mata air yang terbuka memungkinkan dapat terkontaminasi oleh lingkungan sekitarnya. Proses pengambilan air baku yang berasal dari mata air menuju depot air minum isi ulang (DAMIU) harus dilakukan menggunakan mobil tangki yang berbahan tara pangan. Hal ini dilakukan agar air baku tersebut 
tidak tercemar oleh mikroorganisme baik dari lingkungan maupun pada saat perjalanan. Oleh karena itu, dalam kepemenperindag tahun 2004 persyaratan ini sudah sudah dijelaskan. Terdapat $1(3,33 \%)$ DAMIU yang tidak memenuhi syarat dalam hal pengangkutan air baku paling lama 12 jam sampai ke depot air minum dan perjalanan dilakukan desinfeksi. Sedangkan pada 29 $(96,67 \%)$ DAMIU lainnya memenuhi persyaratan. Pada masa pengangkutan air baku untuk Depo Air Minum (DAMIU) juga harus diperhatikan. Pengangkutan air yang melebihi waktu 12 jam dapat memungkinkan berkembangnya mikro organisme yang berbahaya bagi kesehatan (Depkes RI, 2006).

\section{Akumulasi Penilaian Higiene dan Sanitasi DAMIU}

Hasil pelaksanaan higiene sanitasi DAMIU di Kecamatan Banyuwangi, Kabupaten Banyuwangi, Propinsi Jawa Timur adalah sebanyak 28 DAMIU memenuhi syarat karena mendapatkan skor $\geq 70$. Pada 2 DAMIU lainnya tidak memenuhi syarat dikarenakan mendapat skor $<70$. Hal ini sejalan dengan penelitian yang dilakukan oleh Pandeinuwu et al. (2016) yang menjelaskan bahwa kondisi hygiene sanitasi 15 depot air minum isi ulang di terdapat 7 depot $(46,7 \%)$ memenuhi kelaikan fisik dan 8 depot $(53,3 \%)$ tidak memenuhi kelaikan fisik. Oleh karena itu, kepada depot yang belum memenuhi syarat, maka dilakukan pembinaan dan pengawasan. Pembinaan dan pengawasan ini bertujuan untuk mengurangi risiko kesehatan dari air minum yang dihasilkan oleh Depot Air Minum Isi Ulang dan memelihara serta mempertahankan kualitas air minum yang dihasilkan oleh depot air minum isi ulang agar sesuai dengan ketentun peraturan perundangundangan (Menteri Kesehatan Republik Indonesia, 2014)

\section{KESIMPULAN DAN SARAN}

Kesimpulan dari penelitian ini adalah kondisi higiene dan sanitasi di 30 Depot Air Minum Isi Ulang (DAMIU) di Kecamatan Banyuwangi yaitu $28 \quad(93,33 \%)$ DAMIU memenuhi kelaikan fisik, sedangkan terdapat 2 $(6,67 \%)$ DAMIU tidak memenuhi kelaikan fisik berdasarkan hasil penilaian total pada seluruh variabel sesuai formPeraturan Menteri Kesehatan Republik Indonesia Nomor 43 Tahun 2014.

Secara umum, kondisi higiene dan sanitasi di 30 DAMIU di Kecamatan Banyuwangi sudah baik, namun perlu dilakukan upaya pembinaan dan pengawasan secara intensif oleh Dinas Kesehatan Kabupaten Banyuwangi terhadap Depot Air Minum Isi Ulang di Kecamatan Banyuwangi.

\section{UCAPAN TERIMA KASIH}

Penulis mengucapkan terimakasih kepada dosen pembimbing yang telah memberikan masukan dan saran selama penelitian serta teman-teman Peminatan Kesehatan Lingkungan tahun 2019 FKM PSDKU Universitas Airlangga di Banyuwangi yang telah membantu mengambil data dalam proses penelitian.

\section{DAFTAR PUSTAKA}

1] Asfawi, S. 2004. Analisis Faktoryang Berhubungan dengan Kualitas Bakteriologis Air Minum Isi Ulang pada Tingkat Produsen di Kota Semarang. Universitas Diponegoro.

2] BBPOM. 2004. Materi Pelatihan Penyuluhan Keamanan Pangan Buku II. BBPOM, Surabaya.

3] Citra, 2016. 7 Pemanfaatan Sumber Daya Air dalam Kehidupan Manusia. URL https://ilmugeografi.com/ilmubumi/hidrologi/pemanfaatan-sumber-dayaair

4] Depkes RI. 1998. Pedoman Pelatihan Water Technique System Membrane Filter. Ditjen PPM dan PLP Depkes, Jakarta.

5] Depkes RI. 2006. Pedoman Pelaksanaan Penyelenggaraan Hygiene Sanitasi Depot Air Minum. Ditjen PP dan PL, Jakarta.

6] Fitri, S. 2010. Pengaruh Lama Penyimpanan Terhadap Kualitas Air Minum Isi Ulang di Beberapa Depot di Daerah Pasar Baru Padang. Universitas Andalas.

7] Hayu, R.E., Mairizki, F., Ermayulis. 2018. Higiene Sanitasi dan Uji Escherichia Coli Depot Air Minum Isi Ulang (DAMIU) di Kelurahan Pesisir, Kecamatan Lima Puluh, Kota Pekanbaru. Jurnal Kesehatan Vokasional 3.

8] Menteri Kesehatan Republik Indonesia. 2010. Peraturan Menteri Kesehatan Republik Indonesia Nomor.492/MENKES/PER/IV/2010 tentang Persyaratan Kualitas Air Minum. 
9] Menteri Kesehatan Republik Indonesia. 2014. Peraturan Menteri Kesehatan Negara RI No. 43 Tahun 2014 tentang Higiene Sanitasi Depot Air Minum.

10] Nuria, M.C., Rosyid, A., Sumantri. 2009. Uji Kandungan Bakteri Escherichia Coli Pada Air Minum Isi Ulang dari Depot Air Minum Isi Ulang di Kabupaten Rembang. Jurnal Mediagro 5, 27-35.

11] Pandeinuwu, F. V, Umboh, J.M.., Joseph, W.B. 2016. Higiene Sanitasi dan Kualitas Bakteriologis Air Minum pada Depot Air Minum Isi Ulang (DAMIU) Di Kota Tomohon Tahun 2015. Pharmacon 5, 7078.

12] Purnawijayanti, H.A., 2001. Sanitasi Higiene \& Keselamatan Kerja Dlm Pengolh Makanan. Kanisius, Yogyakarta.

13] Purwana, R., 2006. Pedoman Pengawasan Higiene Sanitasi Depot Air Minum Semarang Jawa Tengah: Dinas Kesehatan Propinsi Jawa Tengah.

14] Rahayu, A., Setiani, O., Nurjazuli, 2008. Deteksi Adanya Bakteri pada Air Minum dalam Kemasan Galon.
15] Rietveld, L., van der Helm, A., van Schagen, K., van der Aa, R., van Dijk, H. 2008. Integrated simulation of drinking water treatment. Journal of Water Supply: Research and Technology-Aqua 57, 133 141.

16] Selomo, M., Natsir, M.F., Birawida, A.B., Nurhaedah, S. 2018. Hygiene Dan Sanitasi Depot Air Minum Isi Ulang Di Kecamatan Campalagian Kabupaten Polewali Mandar. Jurnal Nasional Ilmu Kesehatan 1.

17] Sukmara. 2002. Faktor Sanitasi Yang Berhubungan dengan Kontaminasi Coliform Pada Makanan Matang di Tempat Pengelolaan Makanan Daerah Jakarta Selatan. Universitas Indonesia.

18] Sulistyandari, H., Sulistyani, S., Raharjo, M. 2009. Faktor - Faktor Yang Berhubungan Dengan Kontaminasi Deterjen Pada Air Minum Isi Ulang Di Depot Air MInum Isi Ulang (DAMIU) Di Kabupaten Kendal Tahun 2009. Jurnal Kesehatan Lingkungan Indonesia 6. 